\title{
"Case Study: Application for optimizing the product mix problem of linear programming in the Apparel Industry” \\ ${ }^{1}$ Varsha Rathi, ${ }^{2}$ Sangeeta Gupta, ${ }^{3}$ Sweta Srivastav \\ 1,2,3 Sharda University, Greater Noida, India \\ Department of Mathematics \\ ²sangeeta.gupta@sharda.ac.in, ${ }^{3}$ sweta.srivastav@sharda.ac.in
}

\begin{abstract}
The industry has made effective management decision-making techniques possible through surveys and the efficient use of sources and assets.

Linear programming can be used for the optimization problem of product mix. We have to understand the concept behind the optimization problem of product mix is important to get success in industry for meeting customer needs.

The manufacturing profit depends on proper distribution of product material and usage of available production time material and labor resources.

The findings of the study show that the profit of the company and the demand of the product.

Keywords: Linear programming, MATLAB, Optimal,Product mix.
\end{abstract}

\section{AMS SUBJECT CLASSIFICATION: 90B05.}

\section{Introduction}

We are doing research on the optimization problem of product mix. In this paper we have the monthly held resources, product volume, and amount of resources used to produce each unit of product and profit per unit for each product have been collected from the company. Worldwide extension and competition in businesses, industrialists must uplift their operations and practices. LPP is solving the problem and help the managers to take best decision.

For the present study cloth factory at D-24 NoidaSudha garment district (GautambuddhaNagar). At Sudha Garment, our range of fabrics is universal in appeal. We aim to inspire a diverse mic of customers enriching lifestyles globally.

Kellerer, H., \&Strusevich, V.A. (2016) devolved the model for optimizing the half-product and related quadratic Boolean functions: approximation and scheduling applications. Fagoyinbo, I. S.,\&Ajibode, I. A. (2010) worked on application of linear programming techniques in the effective useof resources for staff training. Workie, G. (2017) studied in apparel Industry by applied theoptimization problem of product mix and Linear programming applications.

A.I.Iheagwara, J.Opara, J.I. Lebechi and P.A. Esemokumo (2014) used linear programming problem on Niger Mills Company PLC Calabar. W.B.Yahya, M.K.Garba, S.O.Ige and A.E. 
Adeyosoye (2012) did the work on profit maximization in a product mix company using linear programming. AsReeb and Leavengood (1998) stated, it is a planning process that allocates resources-labor, materials, machines, and capital—in the best possible way so that costs are minimized or profits are maximized.

When defining the product mix, Sudhagarment industry has been faced discrepancy. Theproblem arises from the incompetent use of resources, which makes difficulties to ensure the optimal range of products for maximum profit that also effect the customer needs. Thus, sudha garment be required to go through operations research techniques to result in optimal product mix and total profit. We take four products long kurti, basic kurti, v-neckkurti and collar kurti and then the resource of the product what the demand of the product and the profit. The objective of the study was to suggest linear programming as a decision tool to determine the optimal product mix for maximum profit with available resources.

\section{Methodology}

The data collection procedure was visit in company and face to face interviews with members of management and line supervisors with all records of the cloths and then finalize the concept relevant to the resources held and consumed and the production volume of each product in the company.

Table 1: Resources needed per unit of product.

\begin{tabular}{|l|l|l|l|l|l|l|l|}
\hline \multirow{2}{*}{$\begin{array}{l}\text { Products } \\
\text { (kurtis) }\end{array}$} & \multicolumn{6}{l}{ RESOURCES USED PER UNIT PRODUCT } \\
\cline { 2 - 8 } & $\begin{array}{l}\text { Fabrics } \\
\text { (MTR) }\end{array}$ & $\begin{array}{l}\text { Threads } \\
\text { ( MTR) }\end{array}$ & $\begin{array}{l}\text { Labor } \\
\text { (RS.) }\end{array}$ & $\begin{array}{l}\text { Overheads } \\
\text { (RS.) }\end{array}$ & $\begin{array}{l}\text { Cutting } \\
\text { (MIN) }\end{array}$ & $\begin{array}{l}\text { Sewing } \\
\text { (MIN) }\end{array}$ & $\begin{array}{l}\text { Finishing } \\
\text { (MIN) }\end{array}$ \\
\hline Long Kurti & 3.5 & 5 & 200 & 40 & 15 & $\mathbf{6 5}$ & $\mathbf{1 6}$ \\
\hline Basic Kurti & 2.5 & 6 & 140 & 30 & 13 & $\mathbf{6 0}$ & $\mathbf{2 2}$ \\
\hline V-neck Kurti & 2.6 & 4 & 150 & 60 & 18 & $\mathbf{5 0}$ & $\mathbf{2 0}$ \\
\hline Collar Kurti & 2.8 & 6 & 180 & 55 & 21 & $\mathbf{7 0}$ & $\mathbf{2 5}$ \\
\hline
\end{tabular}

Costumer orders for four kurtiproducts and Seven constraints (fabrics, thread, labor, overheads, cutting, sewing, and finishing time)have been identified. The major items held and consumed is discussed below via tabulation: 
Table 2: Average monthly resources held in quantity/value terms (in Rs.)

\begin{tabular}{|l|c|l|}
\hline RESOURCE TYPE & MEASURING UNIT & HELD VALUE \\
\hline FABRICS & meter & 3270 \\
\hline THREADS & meter & 43835 \\
\hline LABOR & Rs. & 1367900 \\
\hline OVERHEAD & Rs. & 619000 \\
\hline CUTTING & min & 121100 \\
\hline SEWING & $\min$ & 909900 \\
\hline FINISHING & $\min$ & 160400 \\
\hline
\end{tabular}

The case apparel company earned the demand and profit from each product.

Table 3: Demand and profit earned.

\begin{tabular}{|l|l|l|l|l|}
\hline & Long Kurti & Basic Kurti & V-neck Kurti & Collar Kurti \\
\hline DEMAND & 1800 & 3000 & 1300 & 1200 \\
\hline PROFIT & 220 & 250 & 280 & 250 \\
\hline
\end{tabular}

\section{MODEL FORMULATION}

Formulate a given decision problem in mathematical form. Model consists of linear relationships representing a resource constraints and objectivesHowever,the size and complexity of the problem may differ. wide variety of decision-making problems is same.

Linear programming consists of following parameters:

1. That are mathematical symbols of decision variables represents the level of activity of an operation.

2. Parameters/cost coefficients thatare constants and numerical coefficients used in the objective function. 
3. The objective function, which is to be maximized or minimized.

Mathematical formulation: -

The procedure consists of following steps: -

1. The given situation is to find the key decision.

2. Identify the variables and define them as

$\mathrm{Yj}(\mathrm{j}=1,2, \ldots, \mathrm{n})$.

3. State the feasible alternatives: $\geq 0$, for all $\mathrm{j}$.

4. Identify the constraints and express them as linear equations, which are linear function of decision variables of left hand side.

5. Identify the objective function and express it as linear function of decisionvariables.

6. Optimize the objective function either graphically or mathematically.

\section{General form of LPP}

In general, if $\mathrm{C}=\left(C_{1}, C_{2}, \ldots, C_{n}\right)$ is a tuple or set of real numbers, then the function $\mathrm{F}$ of real variables, $\mathrm{y}=\left(y_{1}, y_{2}, \ldots, y_{n}\right)$ is defined by,

$\mathrm{f}(\mathrm{y})=C_{1} y_{1}+C_{2} y_{2}+\ldots+C_{n} y_{n}$

is known as a linear function.

If $\mathrm{g}$ is a linear function and $\mathrm{b}=\left(b_{1}, b_{2}, \ldots, b_{n}\right)$ is a tuple or set of real numbers, then $\mathrm{g}(\mathrm{y})$ $=\mathrm{b}$ is called a linear equation, whereas $\mathrm{g}(\mathrm{y})(\leq, \geq)$ bis called a linear inequality. A linear programming problem (LPP) is one which optimizes (maximizes or minimizes) a

linear function subject to a finite collection of linear constraints.

Formally, any LPP having decision variables can be written in the following form: Optimize,

$$
\sum_{j=1}^{n} C_{j} y_{j}
$$

Subject to $\sum_{j=1}^{n} a_{i j} y_{j}(\leq,=, \geq) b_{i}$

$$
\left\{y_{j} \geq 0, \mathrm{i}=(1,2, \ldots, \mathrm{n}), \mathrm{j}=(1,2, \ldots, \mathrm{n})\right\}
$$

where $C_{j}, a_{i j}, b_{i}$ are constant 


\section{RESULT AND DISCUSSION}

The information collected from the company considering the demands and other data provides estimate for LPP model variables. To set up the model, the first step is to define the decision variables on the number of products to be produced were set.

Let, $y_{1}=$ number of long kurti

$y_{2}=$ number of basic kurt i

$$
\begin{gathered}
y_{3}=\text { number of } \mathrm{v}-\text { neck kurti } \\
y_{4}=\text { number of collar kurti }
\end{gathered}
$$

$\mathrm{Z}=$ total profit during the month

$$
z_{\max }=220 y_{1}+250 y_{2}+280 y_{3}+250 y_{4}
$$

Subject to,

$$
\begin{gathered}
3.5 y_{1}+2.5 y_{2}+2.6 y_{3}+2.8 y_{4} \leq 3270 \text { (fabric) } \\
5 y_{1}+6 y_{2}+4 y_{3}+6 y_{4} \leq 43835 \text { (thread) } \\
200 y_{1}+140 y_{2}+150 y_{3}+180 y_{4} \leq 1367900 \text { (labor) } \\
40 y_{1}+30 y_{2}+60 y_{3}+55 y_{4} \leq 619000 \text { (overhead) } \\
15 y_{1}+13 y_{2}+18 y_{3}+21 y_{4} \leq 121100 \text { (cutting time) } \\
65 y_{1}+60 y_{2}+50 y_{3}+70 y_{4} \leq 909900 \text { (sewing time) } \\
16 y_{1}+22 y_{2}+20 y_{3}+25 y_{4} \leq 160400 \text { (finishing time) } \\
y_{1} \geq 1800, y_{2} \geq 3000, y_{3} \geq 1300, y_{4} \geq 1200 \\
y_{1} \leq 2000, y_{2} \leq 4000, y_{3} \leq 1500, y_{4} \leq 1400
\end{gathered}
$$

\section{MODEL SOLUTION}

Algorithm: To generate the MATLAB program for finding the solution of above linear programming problem.

\% Solve the LPP in MATLAB

$\% f$ is the objective function (but in a minimal form), 
$\%$ A, Aeq, Beq are the matrices,

$\% \mathrm{~b}$ is the limited resource vector,

$\% \mathrm{ub}$ and $\mathrm{lb}$ are the upper and lower bound respectively (demand vector),

$\% \mathrm{x}$ is the vector of number of respective products,

$\%$ fval is the value of the objective function.

$f=\left[\begin{array}{llll}-220 & -250 & -280 & -250\end{array}\right] ; \%$ objective function in minimization.

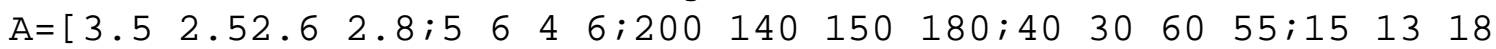

$21 ; 65605070 ; 16222025] ; \%$ constraint matrix

$b=\left[\begin{array}{lllllll}3270 & 43835 & 1367900 & 619000 & 121100 & 909900 & 160400\end{array}\right] ;$ limited

resource vector.

Aeq $=[] ; \mathrm{beq}=[]$;

$u b=\left[\begin{array}{llll}2000 & 4000 & 1500 & 1400\end{array}\right] ; \quad l b=\left[\begin{array}{llll}1800 & 3000 & 1300 & 1200\end{array}\right] ; \%$ demand vector format bank

$[x, f v a l$, exitflag, output $]=\operatorname{linprog}(f, A, b$, Aeq, beq, lb, ub )

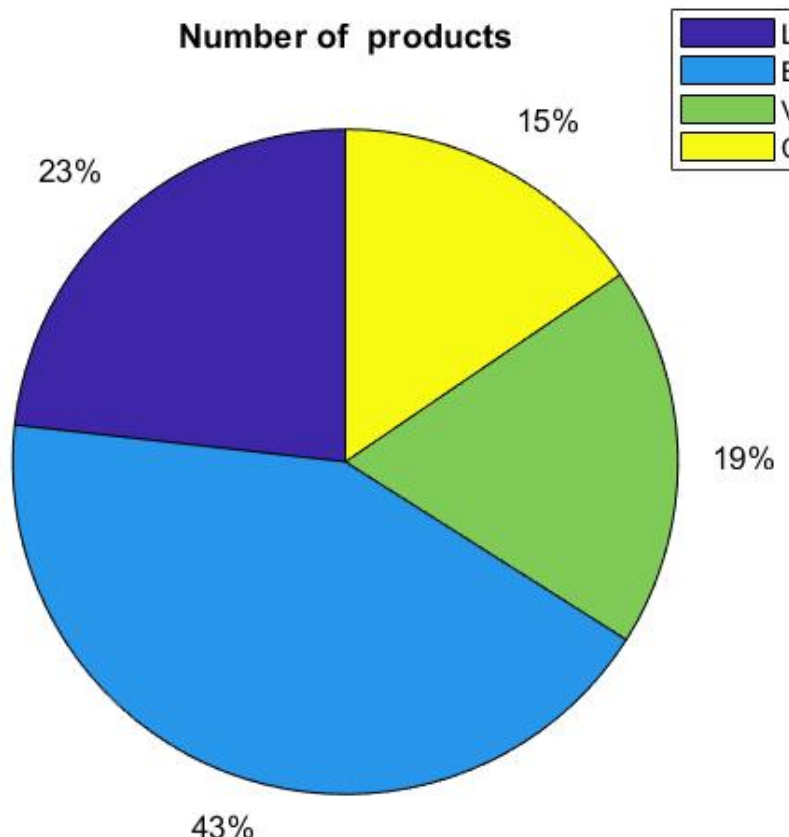




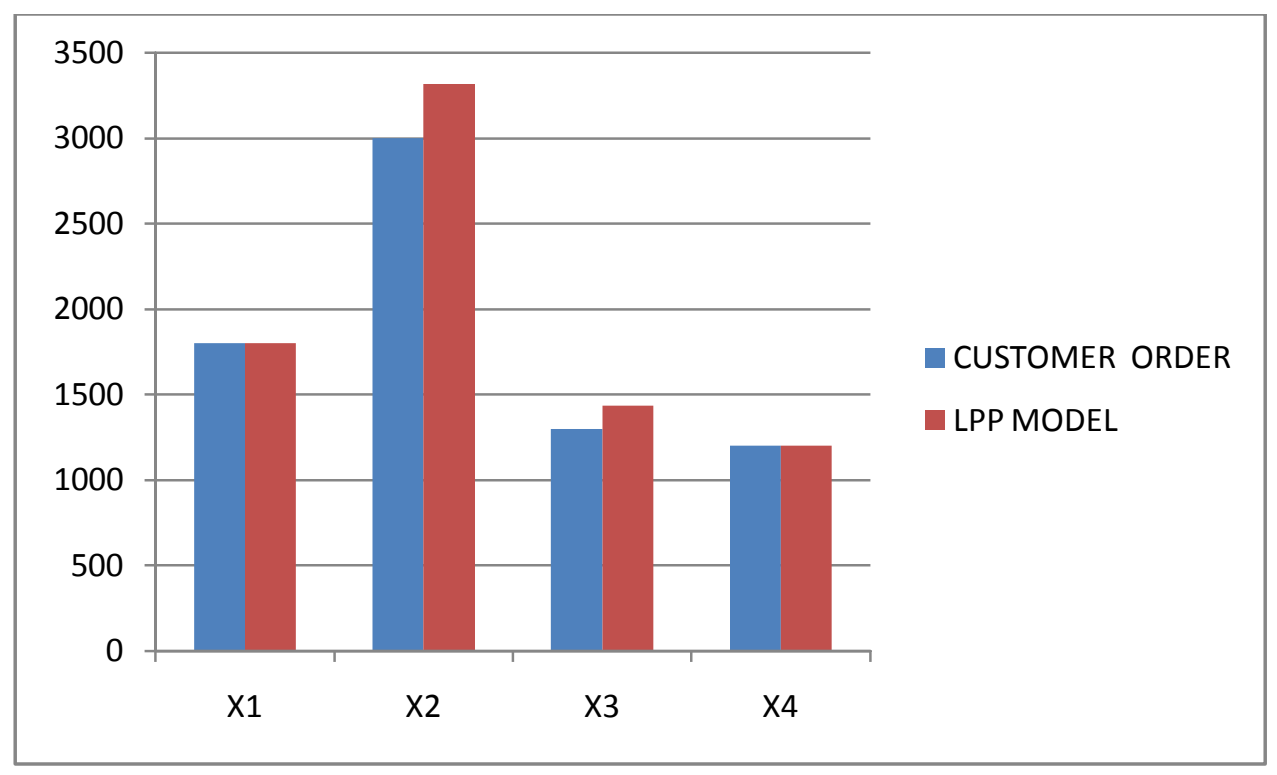

\section{CONCLUSION}

The resources in the apparel manufacturing industry utilization were mentioned as the major constraint. The profits comparison betweenthe production using LPP models and actual production shows the considerable differences. So, we can conclude that cloths industry should use the quantitative research methods of LPP to determine their optimal product mix. The profit of the company can be improved 1926147.06 per month. Use of an operational research technique in the production helps the company to improve its objective.

\begin{tabular}{|l|c|l|}
\hline & Customer orders & LPP model \\
\hline X1 & 1800 & 1800 \\
\hline X2 & 3000 & 3314.71 \\
\hline X3 & 1300 & 1433.82 \\
\hline X4 & 1200 & 1200 \\
\hline & & \\
\hline Max Z $=$ & 1810000 & 1926147.06 \\
\hline & difference $=$ & 116147.06 \\
\hline
\end{tabular}

References:

1. A.I.Iheagwara, J.Opara, J.I. Lebechi and P.A. Esemokumo, “Application of LinearProgramming Problem on Niger Mills Company PLC Calabar”, International Journalof Innovation and Research in Educational Sciences (IJIRES), 1(2),(2014), pp712.

2. A.R. Mohammed and S. S. Kassem, "Product Mix Optimization Scenarios: A Case study for Decision Support Using Linear Programming Approach," 2020International 
Conference on Innovative Trends in Communication and ComputerEngineering (ITCE), Aswan, Egypt,(2020), pp. 50-55.

3. Anieting, A.E., Ezugwu, V.O., \& Ologun, S., “Application of linear programmingtechnique in the determination of optimum production capacity”, IOSR Journal ofMathematics (IOSR-JM), 5(6), (2013) pp 62-65.

4. Ekwonwune, E.N., \&Edebatu, D.C., “ Application of linear programming algorithmin the optimization of financial portfolio of Golden Guinea Breweries Plc, Nigeria”,Open Journal of Modeling and Simulation, 4, (2016), pp 93-101.

5. Ezema, B.I and Amakoml, U., " Optimizing Profit with the Linear ProgrammingModel: A Focus on Golden Plastic Industry Limited, Enugu, Nigeria”,Interdisciplinary Journal of Research in Business, 2 ( 2),(2012), pp 37-49.

6. Fagoyinbo, I. S., \&Ajibode, I. A., “ Application of linear programming techniques inthe effective use of resources for staff training”, Journal of Emerging Trends inEngineering and Applied Sciences (JETEAS), 1(2),(2010), pp 127-132.

7. Hadidi, L., Moawad, O., "The product-mix problem for multiple production lines insequenced stages: a case study in the steel industry”, Int J Adv Manuf Technol 88, (2017), pp 1495-1504.

8. JonnalaSubbareddy , M.Bhavani, G.Kartheek , J. Venkata Somi Reddy , "optimization of a product mix in a paper mill - a case study", International Journal of Advance Engineering and Research Development Volume 5, Issue 04, (2018), pp 1-6.

9. Kellerer, H., \&Strusevich, V.A., "Optimizing the half-product and related quadratic Boolean functions: approximation and scheduling applications", Annals of Operations Research, 240,(2016), pp 39-94.

10. N. P.\&Iwok, I.A., "Application of Linear Programming for Optimal Use of Raw Materials in Bakery Akpan”, International Journal of Mathematics and Statistics Invention (IJMSI), 4(8),(2016), pp 51-57.

11. P. J. Nikumbh , S. K. Mukhopadhyay, Bijan Sarkar and Ajoy Kumar Dutta, "Rough Sets Based Product Mix Analysis", International Journal of Advancements inTechnology, Vol 2, No 3 (July 2011), pp 382-399.

12. Shaheen, S. and Ahmad, T., "Linear Programming Based Optimum Resource Utilization for manufacturing of Electronic Toys”. International Research Journal of Engineering and Technology (IRJET), 2 (1),(2015), pp 261-264.

13. W.B.Yahya, M.K.Garba, S.O.Ige and A.E. Adeyosoye, "Profit Maximization In AProduct Mix Company Using Linear Programming”, European Journal of Business and Management, 4(17), 2012, 126-131.

14. Workie, G., "The optimization problem of product mix and Linear programming applications: Study in apparel Industry”. Open Science Journal, Vol. 2(2)(2017), pp 111. 